\title{
Plurinacionalismo y estatalidad: el caso de Irlanda del Norte *
}

\author{
MARGARET CANOVAN \\ Keely University, UK
}

\begin{abstract}
«Events, past and present... are the true, the only reliable teachers of political scientist. Once such and event... has happened, every policy, theory and forecast of future potentialities needs re-examination»
\end{abstract}

Hannah Arendt ${ }^{1}$

Los acontecimientos de la década pasada - con sucesos que se extienden desde los horrores de la limpieza étnica en la antigua Yugoslavia a la euforia que acompañó la liberación nacional y democrática de las revoluciones de 1989 - han forzado a los teóricos políticos a repensar el significado político de la identidad nacional. Algunos de estos acontecimientos han puesto de relieve las dificultades de la democracia liberal en los Estados plurinacionales. Simultáneamente, en otra zona de Europa occidental han tenido lugar acontecimientos de gran trascendencia, en una región donde el Estado liberal democrático se ha visto tradicionalmente sometido a fuertes tensiones como consecuencia de la presión de lealtades nacionales enfrentadas. Durante los últimos años, el «proceso de paz» en Irlanda del Norte ha presentado un panorama de iniciativas imprevistas y cambios inciertos que todavía no ha llegado a su fin. Hay dos razones que vinculan la discusión sobre el plurinacionalismo ${ }^{2}$ y la estatalidad al caso de Irlanda del Norte. Por una parte, su historia ha sido vista como un ejemplo particularmente claro de las dificultades para establecer y consolidar un Estado liberal democrático en un territorio disputado por naciones rivales ${ }^{3}$. Por otra, los recientes acontecimientos parecen ser un buen ejemplo de la tesis de que el viejo paradigma del Estado-nación soberano ha sido superado y de que algunas nuevas estructuras políticas más flexibles son capaces de apaciguar las tensiones nacionales. Como veremos, el examen de este caso nos permitirá modificar las posiciones particularmente simplistas de los dos elementos de este argumento.

El propósito de este artículo es utilizar el ejemplo de Irlanda del Norte como marco para la discusión en torno a los cambios en la naturaleza del Estado y sus vínculos con la identidad nacional. La estructura del artículo es la siguiente. En la sección I se expondrán brevemente los términos del debate teórico. En su primera parte, I (a), se examinarán las razones por las que puede esperarse que los Estados liberales democráticos tengan dificultades allí donde la condición nacional sea disputada, mientras que la sección I (b) se detiene en las razones que permiten suponer que los cambios recientes en la soberanía del Estado pueden haber creado nuevas condiciones políticas que se ajusten mejor a las sociedades plurinacionales. Ambas vertientes del argumento se presentarán enérgicamente. En la sección II, la discusión

* Traducción de Ana María López Sala y Valeriano Esteban. 
se desplaza desde lo general al caso particular del destino de Irlanda del Norte en el conjunto del Reino Unido. Mediante un recorrido por la historia de la provincia, la sección II (a) considera qué elementos de la misma sustentan la primera parte del argumento, así como las concepciones tradicionales del Estado-nación soberano. La sección II (b) se concentra en el «proceso de paz» de la década de los noventa y su culminación en la firma del acuerdo de paz en Belfast el día de Viernes Santo de 1998. Mi intención es dilucidar si algunos de los aparentes progresos desarrollados en esta dirección pueden atribuirse a los cambios en la identidad nacional tal y como se describen en la sección I (b). En el momento en que se escribe este artículo la ejecución del acuerdo está estancada y el pronóstico es desolador. La sección final considera las implicaciones de la parálisis actual e intenta mostrar algunas conclusiones. Una de ellas hace referencia a la importancia de la contingencia histórica y a los peligros de una generalización poco fundada en torno al tema del nacionalismo. Por el momento, sin embargo, hemos de proceder con cautela y considerar los argumentos a favor y en contra de la tesis que sostiene que la democracia liberal se desarrolla mejor en los Estados uninacionales.

SECCión I: ¿MÁs ALLÁ DEL Estado-NACión?

I (a). El Estado-nación soberano y los problemas de la nacionalidad múltiple

Durante la mayor parte del siglo xx, el modelo dominante de Estado democrático liberal fue aquel constituido por una comunidad política soberana territorialmente delimitada e integrada por ciudadanos. En este modelo clásico (adoptado con entusiasmo a finales de siglo por los antiguos países comunistas del centro y el este de Europa) se asume que la población, en posesión, a su vez, del Estado, constituye el conjunto de la ciudadanía. Esta ciudadanía comparte la autoridad soberana sobre el territorio, y tanto su lealtad como su solidaridad dotan de poder y seguridad al Estado. Aunque en este modelo la naturaleza y constitución de la ciudadanía haya sido definida en raras ocasiones, se ha asumido, por lo general, teórica y prácticamente, que el Estado no pertenece a un conjunto de individuos que residen por casualidad en un territorio, sino a aquellos que integran la nación, «una comunidad de ciudadanos» (usando la terminología de Dominique Schnapper ${ }^{4}$ ) que reconoce al Estado y a sus leyes como propias y acepta también la legitimidad de sus fronteras. Se ha afirmado con cierta frecuencia que las naciones concebidas en términos cívicos proporcionan una base más sólida para los Estados democráticos liberales que las constituidas en términos étnicos ${ }^{5}$, pero ésta es una matización de menor importancia ante el principio general de la nacionalidad, tan omnipresente que ha llegado a hacerse invisible en la política moderna ${ }^{6}$. La aceptación del principio de «autodeterminación» confirma la convicción de que no es legítimo que «nuestra gente» ejerza poder sobre «los otros» o sea gobernada por «ellos»y, más aún, da fe de la creencia de que los individuos pueden ser identificados como miembros de una comunidad nacional distintiva al margen de su estatus legal.

Aunque el modelo de comunidad política democrática liberal sea el Estado-nación, sólo algunas fronteras estatales se han ajustado a las divisiones nacionales, particularmente fuera de la Europa Occidental. Las dificultades resultantes han suministrado numerosas pruebas en apoyo de la teoría de que las comunidades políticas en donde se aprecia un desajuste entre el Estado y la nación son terreno poco propicio para el desarrollo de la democracia liberal. Los problemas a los que se enfrentan las comunidades políticas 
plurinacionales son fáciles de describir. En mayor medida que cualquier otra forma de gobierno, la democracia liberal descansa no en la fuerza, sino en la autoridad legítima, sancionada por la solidaridad y el acuerdo popular. La nacionalidad es uno de los factores que movilizan eficazmente este tipo de poder por consenso y los Estados democráticos liberales han ofrecido pruebas sobresalientes de la estabilidad y prosperidad que proporciona la lealtad y la solidaridad nacional a las instituciones políticas. Por el contrario, precisamente porque la nacionalidad es capaz de generar tal poder colectivo, la presencia de diversas naciones en un Estado tiende a generar problemas a las democracias liberales, particularmente si la nación más poderosa está en posesión del Estado y las más débiles no admiten la legitimidad de sus fronteras. Estas circunstancias ponen a prueba la democracia, desde el momento en que la nación minoritaria puede interpretar que los resultados electorales no reflejan la voluntad de la ciudadanía. Las normas liberales basadas en la ley y los derechos resultan igualmente difíciles de mantener cuando las fuerzas de la ley y del orden son percibidas por la minoría como instrumentos «de ellos» y no «nuestros». $\mathrm{La}$ nación mayoritaria y sus autoridades pueden, en estas circunstancias, considerar a la nación minoritaria como desleal y potencialmente peligrosa, reforzando así un hipotético círculo vicioso.

Dado que estas tensiones nacionales pueden minar el gobierno representativo y el imperio de la ley, hay razones para pensar a simple vista que la democracia liberal debe hacer frente a serias dificultades en el interior de los Estados plurinacionales. Comparemos, por ejemplo, la experiencia poscomunista de la uninacional Eslovenia con la de otras provincias de la antigua Yugoslavia que no tuvieron la fortuna de ser territorios en donde se diera este acoplamiento entre Estado y Nación ${ }^{7}$. En fechas recientes, sin embargo, muchos expertos en teoría política han defendido que este tipo de análisis es cada vez menos ajustado a la realidad actual, debido a los cambios experimentados en la naturaleza del Estado moderno. De acuerdo con estos argumentos, el modelo clásico de Estado-nación como una posesión soberana de un único pueblo es cada vez menos relevante en la política contemporánea, particularmente en el caso de Europa. Las transformaciones experimentadas en la naturaleza de la soberanía, la ciudadanía, la democracia e, incluso, la nacionalidad han creado nuevos tipos de instituciones políticas más flexibles y más armónicas con el pluralismo interno. En estas nuevas condiciones, los vínculos entre la nación y el Estado han perdido una parte de su significación, de tal manera que la presencia en el interior de un Estado de más de una nacionalidad no tiene por qué resultar problemática para la democracia liberal. Consideremos, por ello, algunas de estas transformaciones.

\section{I (b). ¿El fin del Estado-nación soberano?}

El cambio más significativo que han debido afrontar los Estados-nación europeos en el curso de la segunda mitad del siglo pasado ha sido de naturaleza militar: la pérdida tanto de la capacidad como de la necesidad de proteger su territorio contra la agresión. La disposición de los ciudadanos a luchar y morir por su patria ha sido un rasgo tradicional del Estado-nación clásico. A la inversa, los Estados que se ven en la necesidad de proteger sus fronteras de las naciones vecinas no pueden permanecer indiferentes ante el hecho de que una parte de su población tenga dudas de hasta dónde llega su lealtad. Sería poco acertado por parte de los teóricos políticos acostumbrados a la desmilitarización de las fronteras de la Europa Occidental suponer que las consideraciones de esta naturaleza 
son anacrónicas ${ }^{8}$. En esta parte privilegiada del mundo, el cambio ha sido notable. La Segunda Guerra Mundial y la larga confrontación entre la OTAN y el Pacto de Varsovia muestran que ningún Estado de Europa puede ser militarmente autosuficiente. Desde el final de la Guerra Fría muchos Estados europeos han dejado atrás la apremiante sensación de tener enemigos militares, y actual convicción de que bajo ninguna circunstancia es posible una guerra entre Estados ha conducido a una nueva situación en la que las fuerzas armadas son concebidas como recursos para la intervención humanitaria más que como instrumentos de defensa del territorio nacional.

Una consecuencia de este cambio ha sido que el control soberano sobre el territorio se ha transformado en una cuestión mucho menos importante de lo que había sido nunca tras el Tratado de Westfalia ${ }^{9}$. Las fronteras siguen teniendo su importancia, pero, al margen de ciertos conflictos ligados al orgullo nacional que suscitan sensibilidad pública (como el caso de Gibraltar), los europeos occidentales se encuentran mucho más preocupados por los flujos de inmigrantes irregulares que por la invasión de ejércitos extranjeros. El desarrollo de la Unión Europea, nacida de la experiencia de inseguridad nacional de la Segunda Guerra Mundial, ha limitado la relevancia del territorio y ha erosionado la soberanía estatal. Los Estados no sólo han tenido que ceder una parte de su soberanía a la nueva supraestructura europea, sino que la misma naturaleza de la soberanía ha cambiado. Los Europeos occidentales han llegado a acostumbrase a esta nueva situación. Gracias a su capacidad para movilizar el consentimiento de sus poblaciones, los Estados son todavía los actores principales del poder, pero actualmente se encuentran habituados a actuar en común, imponiéndose a sí mismos restricciones impensables hace unas generaciones ${ }^{10}$. La cooperación en el ámbito de la Unión Europea es uno de los ejemplos más sobresalientes de una tendencia general en la que los Estados, aunque permanecen formalmente soberanos, han cedido parte de su soberanía a través de la firma de acuerdos vinculantes de naturaleza intergubernamental en aspectos que se extienden desde la protección de los derechos humanos a la promoción del libre comercio y la reducción del efecto invernadero ${ }^{11}$.

Uno de los desarrollos recientes más notables ha sido el establecimiento de un orden legal internacional, cuyo ejemplo más sobresaliente es la creación del Tribunal Europeo de Derechos Humanos. De consuno con la ciudadanía europea, este nuevo orden ha conseguido que los derechos de los individuos sean menos dependientes que nunca de la pertenencia a una nación concreta que se encuentre en control del Estado. Por añadidura, el derecho internacional ha impuesto límites a las actividades de los legisladores que representan a la nación mayoritaria en el interior de un determinado Estado. La concepción clásica de una comunidad política ejerciendo la soberanía en el interior de su territorio ha sido erosionada, asimismo, por los aspectos económicos y demográficos de la globalización. Mientras que los imperativos del mercado global reducen el alcance de las decisiones económicas soberanas, el flujo de personas a través de las fronteras ha avivado la diversidad interna de las poblaciones y ha desdibujado la imagen de una nación única y soberana. La respuesta liberal a estas situaciones, en forma de un nuevo reconocimiento de la diversidad cultural y un compromiso con la integración del pluralismo social, ha suministrado un nuevo lenguaje multicultural del que se espera que ayude a gestionar mejor las tensiones entre naciones. Las modernas comunicaciones y el desarrollo de «la opinión pública internacional» ofrecen a los grupos hostiles algunos incentivos para trasladar sus demandas del lenguaje de la 
soberanía al discurso de los derechos culturales.

Estas transformaciones han servido, en sí mismas, para alterar las concepciones dominantes de la política democrática, en forma de un debilitamiento de la asociación entre la democracia y la voluntad un pueblo soberano. Las redes de relaciones internacionales y los compromisos descritos han trasladado el énfasis de la democracia en los acontecimientos que se producen en el interior de un territorio a la participación en un orden legal internacional y de negociación donde intervienen múltiples actores ${ }^{12}$. La creciente sensibilidad ante los intereses y puntos de vista plurales en el interior de cada Estado ha contribuido a fortalecer que la democracia se entienda como una cuestión de diálogo más que como un ejercicio de la voluntad soberana. Si esta discusión es concebida idealmente como un discurso habermasiano o (de forma más pragmática) como una cuestión de negociación y compromiso, su efecto es realzar el carácter inclusivo y hacer de la democracia un asunto menos sujeto al juego de las mayorías y a la confrontación. Por esta razón se está prestando más atención a una tradición de la teoría y práctica democrática que durante años despertó un interés minoritario. Me refiero a la «democracia consociativa» que Arend Lijphart, su más destacado defensor, bautizó como «la política del compromiso», caracterizada por acuerdos elaborados de responsabilidad compartida que hacen posible que la democracia liberal funcione en sociedades divididas ${ }^{13}$.

Los cambios que acabamos de catalogar permiten caracterizar la política moderna practicada en la Europa Occidental como una política más compleja, flexible y con perfiles menos nítidos que los del modelo típico ideal de Estado-nación descrito anteriormente. Pero, ies este nuevo tipo de política menos dependiente de la movilización popular y más adaptable a la diversidad social, incluso a las diferencias nacio- nales? Aquellos que ven una solución a los conflictos nacionales en este mundo posmoderno de fluidez caleidoscópica también retratan la nacionalidad como una entidad menos sólida y más flexible de lo que aparece en la visión clásica. Valiéndose de la influyente definición de Benedict Anderson de la «nación» como «comunidad imaginada» ${ }^{14}$, algunos teóricos llegan a la conclusión de que la lealtad basada en esa imaginación puede ser reconstruida de forma menos conflictiva ${ }^{15}$. Otros teóricos han intentado desligar la conciencia de pertenencia a una nación de la aspiración política por controlar el Estado y el territorio, reconceptualizando la nacionalidad como una identidad personal $\mathrm{y}$, por lo tanto, asimilando el plurinacionalismo al discurso del multiculturalismo ${ }^{16}$. Una idea que ha atraído a muchos intelectuales y algunos nacionalistas es la de una Europa futura en donde la soberanía de los Estados actuales se haya debilitado, al mismo tiempo que las naciones y subnaciones de Europa (constituidas por los individuos que optan libremente por ser sus miembros) coexistan armónicamente bajo el paraguas de una polis europea que defienda iguales derechos civiles para todos y suministre a sus distintos miembros «un patriotismo constitucional» habermasiano ${ }^{17}$

Esta visión no es todavía una realidad y puede que nunca llegue a serlo. Pero la cuestión que debemos considerar en este artículo es si, al margen de sus méritos en épocas anteriores, el modelo de Estado-nación clásico dificulta el logro de la democracia en los Estados plurinacionales, independientemente de si esta nueva tendencia postnacional y postmoderna de la política europea ha cambiado algunas reglas del juego y ha debilitado algunas posiciones enquistadas. A la luz de este debate teórico, me centraré en uno de los casos más sobresalientes de conflicto originado por el desacoplamiento entre Estado y nación en la Europa Occidental, el 
caso de Irlanda del Norte. ¿Hasta qué punto la historia de esta región sustenta la afirmación de que la democracia liberal no funciona sin una adecuada correspondencia entre el Estado y la nación?, ¿proporciona evidencia el «proceso de paz» de la pasada década de que las nuevas condiciones postnacionales están haciendo posible, en último término, la resolución de estas disputas? Como veremos, el análisis de estos acontecimientos nos obligará a modificar ambos términos del argumento propuesto, complicando el modelo típicoideal de Estado-nación y matizando la tesis «postnacional».

Sección II: El caso de Irlanda del Norte

\section{II (a). Nacionalismo versus Estado-nación: la turbulenta historia de Irlanda del Norte}

El primer elemento que es necesario destacar en el caso de Irlanda del Norte, así como en otros casos caracterizados por una larga historia de conflictos nacionales, es que se da un profundo desacuerdo tanto entre las partes implicadas como entre los observadores externos en torno a la naturaleza y las causas del conflicto, sus acontecimientos clave y los puntos en litigio. Es imposible realizar un análisis completamente neutral y los esfuerzos de imparcialidad desarrollados en este artículo no pueden aspirar a evitar críticas desde algunos ámbitos ${ }^{18}$. Dicho esto, es difícil sostener que Irlanda del Norte haya sido en el siglo $\mathrm{xx}$ un caso modelo de democracia liberal. Pensemos, por ejemplo, en la violencia desencadenada durante los difíciles últimos cuarenta años: cerca de tres mil muertos en una población de algo más de un millón y medio de habitantes ${ }^{19}$. Tres partes han estado implicadas en la violencia. La primera la constituye el ejército del Reino Unido, cuya autoridad legal en el territorio es reconocida por otros Estados, con la excepción, hasta fecha reciente, de la República de Irlanda ${ }^{20}$. Su objetivo, desde su propio punto de vista, es el convencional de defender el territorio contra ataques terroristas. La segunda parte implicada en la violencia son las fuerzas paramilitares que representan la causa del nacionalismo irlandés (en especial el Ejército Republicano Irlandés) y cuyo objetivo es liberar el territorio de la soberanía británica a través de la lucha armada. También reclaman su derecho a proteger a «su pueblo» (los «nacionalistas» y la minoría católica de Irlanda del Norte) de los ataques de las fuerzas de seguridad británicas y de la tercera parte implicada en la violencia: los «lealistas». Éstos están representados por los paramilitares rivales que dicen defender a la mayoría protestante unionista en la provincia contra las amenazas presentadas por el nacionalismo irlandés en general y por el IRA en particular. Una de las razones de la insolubilidad de la disputa tanto en la esfera política como en la militar es, como veremos, que siempre ha habido más de dos partes implicadas.

El conflicto que se desencadenó en la década de los años sesenta puso fin al período de paz que siguió a la división de la isla en los años veinte. La división fue un intento del gobierno británico de reconciliar dos demandas absolutamente opuestas: por un lado, la demanda de autodeterminación cada vez más combativa por parte de la mayoría nacionalista irlandesa (en su mayoría católica) del conjunto de la isla, y, por otro, el igualmente claro y combativo rechazo de los unionistas (en su mayoría protestantes) a abandonar el dominio británico y convertirse en una minoría dentro de un Estado católico irlandés. El difícil compromiso de la separación permitió que tres cuartas partes del territorio de la isla se constituyeran en un Estado prácticamente independiente ${ }^{21}$, mientras que la esquina nororiental predominantemente unionista permaneció anexionada al 
Reino Unido, con su propia administración y parlamento provincial. En la administración norirlandesa la mayoría unionista protestante retuvo durante cuarenta años el poder en sus manos, mientras que la creciente minoría católica fue excluida del poder. En los años sesenta, esta situación desembocó en una ola de violencia entre las dos comunidades, con la aparición de fuerzas paramilitares en ambos lados y en la intervención del ejército británico. En 1972 el gobierno británico tomó la decisión de asumir de nuevo el control directo sobre la provincia. A lo largo de las décadas siguientes el gobierno británico realizó distintos intentos, sin éxito, de debilitar el terrorismo y de crear un nuevo compromiso político en la provincia. Sin embargo, en los 90, la situación mejoró notablemente: el IRA y otras fuerzas paramilitares declararon el alto al fuego, mientras lentas y tortuosas negociaciones con los representantes políticos de las comunidades unionista y nacionalista de Irlanda del Norte condujeron finalmente y contra todo pronóstico a lo que en su momento pareció ser la promesa de una auténtica resolución del conflicto. Este acuerdo, firmado el día de Viernes Santo de 1998, estableció nuevas instituciones de poder compartido, en las que la responsabilidad de la provincia descansa tanto en los unionistas protestantes como en los nacionalistas católicos y confirma el giro del conflicto violento hacia la política democrática. Sin embargo, la puesta en práctica de este acuerdo, resultó ser tan difícil como negociarlo, y las perspectivas actuales no son halagüeñas.

Este artículo no pretende resolver un problema tan complejo como el norirlandés. Solamente nos interesa la cuestión específica de qué es lo que nos puede aportar la experiencia de Irlanda del Norte acerca de las posibilidades y los problemas de la democracia liberal en un Estado plurinacional. Es ésta una cuestión a la que muchos nacionalistas irlandeses de corte tradicional darían una respuesta aparentemente sencilla. De acuerdo con la perspectiva nacionalista clásica, los problemas de Irlanda del Norte se derivan de la falta de correspondencia entre el Estado y la nación: por decirlo con más precisión, están causados por la continuada presencia de un Estado británico extraño y de sus fuerzas de ocupación en lo que de hecho es territorio nacional irlandés. La liberación de Irlanda, parcialmente lograda en 1921, estaría por completar. Y dado que el problema se define como un caso de ocupación extranjera, una vez que las fronteras vuelvan a su debido lugar y toda la isla de Irlanda quede unida en un solo Estado-nación, las causas del conflicto desaparecerán y la democracia liberal prevalecerá como lo hace en los otros Estados-nación de Europa.

De acuerdo con la narración tradicional nacionalista, la historia de Irlanda es una sucesión de acontecimientos trágicos y heroicos, un relato de lucha, sufrimiento popular, opresión imperialista y de una liberación todavía por conseguir. Irlanda fue conquistada hace siglos por los británicos, y las rebeliones periódicas de los nativos irlandeses fueron brutalmente reprimidas. Los conquistadores se quedaron con la tierra, persiguieron la religión irlandesa (el catolicismo), reprimieron el uso de la lengua y la cultura irlandesa y fueron responsables de los efectos de la terrible hambruna de la patata del siglo XIX que redujo la población mediante la emigración y la muerte por inanición. La movilización nacional que consiguió liberar la mayor parte de la isla todavía continúa la lucha para liberar el resto $\mathrm{y}$, aunque la mayor parte de los nacionalistas condenan la violencia paramilitar, muchos de ellos definen el IRA como un movimiento de liberación nacional antes que como un grupo terrorista.

Volviendo a lo dicho anteriormente, no hay narración imparcial de la historia de Irlanda. Pero si partimos de nuestro interés 
por la relación entre nacionalismo y Estado, es necesario hacer dos observaciones importantes a esta dramática narración nacionalista: la primera se refiere a la naturaleza del Estado-nación británico y la segunda a la identidad nacional de los protestantes unionistas. En primer lugar, la imagen del Reino Unido como un Estado extranjero inexorable no acierta a representar la complejidad de la nacionalidad británica, que es una cuestión de gran interés en el contexto presente. El Reino Unido, o, en cualquier caso, Gran Bretaña demuestra que, en algunas circunstancias, es posible desarrollar una nacionalidad «estratificada», en la que las subnaciones (inglesa, escocesa y galesa) viven juntas en una especie de armonía democrática liberal dentro de una identidad nacional británica incluyente, en donde no se cuestionan las fronteras de la identidad nacional, tan dolorosamente relevantes en el caso de Irlanda del Norte. Esto no demuestra, por supuesto, que las identidades de este tipo, incluyentes y armoniosas, puedan ser creadas a voluntad, o que se pueda esperar de ellas que digieran cualquier subnacionalidad: por el contrario, ésta ha fracasado llamativamente a la hora de incorporar la identidad nacional irlandesa. A pesar de esto, es evidente al menos que las naciones varían. No tienen que ser, necesariamente, una nación única e indivisible con el fin de existir y estar en posesión de un Estado, y su existencia y fronteras dependen significativamente de contingencias históricas ${ }^{22}$. Una contingencia histórica particularmente relevante en el caso británico viene dada por el hecho de que durante el siglo XVII, cuando la identidad inglesa empezó a expandirse para formar la identidad británica, incorporando en el camino a muchos escoceses, galeses (y algunos irlandeses) dentro de la poderosa nación imperial, fue precisamente el anticatolicismo y la defensa de un protestantismo estridente, lo que sirvió para dotarles de un sentimiento de unidad en las guerras, casi continuas, contra Francia ${ }^{23}$. Junto con el legado de las anteriores disputas sobre la sucesión al trono británico, la perpetua discriminación hacia los católicos afectó particularmente a los irlandeses. Sin embargo, es concebible que los intentos tardíos de incorporar a los irlandeses pudieran haber funcionado. Pero la eliminación de la discriminación hacia los católicos en el siglo XIX y la garantía de representación parlamentaria en igualdad de condiciones fue contrarrestada por la movilización nacionalista irlandesa acuciada no sólo por los agravios económicos y la expansión de las ideas nacionalistas en toda Europa, sino por un factor local y específico que reforzó el sentido de una identidad separada: la tensión y la violencia endémica en Irlanda entre los irlandeses nativos y la gran comunidad descendiente de los colonos protestantes.

Ahora bien, el segundo elemento que omite la narración nacionalista lo constituye precisamente el arraigo histórico de la comunidad protestante, concentrada en el extremo nordeste de la isla, furiosamente británica y resuelta a no ser incorporada a una nación católica irlandesa. El conflicto en Irlanda del Norte no es (como les gusta pensar a los nacionalistas) un problema entre dos partes, el pueblo irlandés y el Estado británico. Unida a la historia de la conquista de la población irlandesa nativa por parte de los británicos se encuentra un conflicto ulterior: la larga y sangrienta historia de miedo, odio y violencia entre los nativos irlandeses y los descendientes de los colonos protestantes establecidos en Irlanda en el siglo XVII. La comunidad protestante unionista mantiene viva la memoria de las luchas acaecidas durante ese siglo para garantizar que la monarquía británica continuase siendo protestante y parlamentaria, y no católica y absoluta. Esta herencia se simboliza vívidamente en la marcha anual de la orden de Orange, con sus estandartes e insignias, con la que se celebra el triunfo de Gui- 
llermo de Orange sobre Jacobo II, y especialmente la batalla de Boyne de $1690^{24}$. Fuertemente leales al Reino Unido, los unionistas han mantenido tensas relaciones con los sucesivos gobiernos británicos, bajo la sospecha de confabulación con los nacionalistas irlandeses en contra de sus intereses. A principios del siglo $\mathrm{xx}$ fue su temor a convertirse en una minoría perseguida dentro de un Estado irlandés católico lo que bloqueó los planes británicos de autogobierno para el conjunto de la isla de Irlanda e impulsó la división de 1921, acompañada, como es habitual en estos casos, por violencia entre comunidades.

Este intento de resolver el problema nacional a través de la división del territorio no satisfizo a ninguna de las partes implicadas, puesto que ninguna creyó que fuera permanente. Los nacionalistas irlandeses estaban convencidos de que les habían enajenado de la cuarta parte de su legítimo territorio, y continuaron negando la legitimidad de la frontera. Mientras tanto los unionistas, aunque en posesión de su propia parte de la isla, temían al Estado irlandés del sur, desconfiaban del gobierno británico y consideraban a la minoría católica nacionalista como desleal y peligrosa. La abierta discriminación no hizo sino empeorar esta situación. A los cuarenta años de paz difícil en Irlanda del Norte le sucedieron, desde mediados de los sesenta, tres décadas de violencia comunitaria e intervención militar. ¿Qué es lo que podemos extraer de esta historia acerca de la relación entre las diferencias nacionales y los Estados democráticos liberales?

A la luz de la experiencia en Irlanda del Norte, deberíamos, en primer lugar, estar advertidos contra la tentación de llegar a la conclusión demasiado simplista de que el éxito de la democracia liberal requiere una correspondencia directa entre la nación y el Estado. El Reino Unido demuestra, en sí mismo, que en determinadas circunstancias es posible que las sub- naciones compartan una única lealtad y supranacionalidad. Pero la experiencia de Irlanda del Norte sugiere que la lealtad nacional es un factor clave: la nacionalidad es crucial en la medida en que determina la lealtad al Estado y la aceptación de la legitimidad de las fronteras. La cuestión de la lealtad es, por tanto, la diferencia sustantiva entre el caso irlandés y el británico. Los grupos nacionalistas escoceses y galeses que han negado la legitimidad del Reino Unido, han recibido poco apoyo popular: el Estado y sus fronteras han sido aceptados sin reservas por la mayoría de la población como algo propio, especialmente en tiempos de crisis militar. Por el contrario, el lema irlandés «el peligro de Inglaterra es la oportunidad de Irlanda», ilustra el rasgo crucial que ha convertido el conflicto en algo tan difícil de resolver, y tan destructivo para una política democrática liberal. Por razones que son perfectamente comprensibles a la vista de la mayor parte de su experiencia histórica dentro del Reino Unido, los nacionalistas irlandeses no han aceptado la legitimidad del gobierno británico en la isla de Irlanda, amenazando de este modo el más fundamental de los intereses del Estado moderno clásico, la seguridad militar ${ }^{25}$.

La cuestión de la lealtad se simboliza por el estatuto de la frontera entre Irlanda del Norte y la República de Irlanda, y merece atención. Este caso se diferencia en gran medida de muchos otros, aparentemente similares, en los cuales puede haber tensiones entre comunidades étnicas o culturales, pero las rivalidades no implican un cuestionamiento serio de las fronteras. Una disputa territorial como la que se da en Irlanda del Norte se resiste a una solución alcanzada por medios democráticos. Ante el problema de las fronteras, los demócratas pueden pensar que quien debe expresar voluntad de unirse a la República de Irlanda o permanecer dentro del Reino Unido a través de un referéndum es el «pueblo de Irlanda del Norte». 
Pero esto presupone un acuerdo previo acerca de quién constituye el pueblo en cuestión. Un referéndum como éste fue celebrado de hecho dentro de Irlanda del Norte en 1973. Su resultado —el 98,8 por 100 votó a favor de permanecer dentro del Reino Unido- fue rotundo, pero también engañoso, ya que la participación se redujo prácticamente a la comunidad protestante. La minoría nacionalista, sabiendo que serían vencidos dentro de la provincia, boicoteó la consulta con el argumento de que no se había convocado al electorado debido. Desde su punto de vista, «el pueblo» a consultar era el de la población del conjunto de la isla, no sólo la parte dominada por los unionistas.

Las cuestiones de legitimidad y lealtad también se resisten a la solución democrática en otro punto clave: en sus implicaciones respecto al uso legítimo de la fuerza. Desde el punto de vista de los unionistas y del gobierno británico, el Reino Unido es el titular (como cualquier otro Estado) del monopolio del uso legítimo de la fuerza dentro de su propio territorio, que incluye Irlanda del Norte. Cualquier otro individuo o grupo que haga uso de la fuerza o de su amenaza dentro de ese territorio es considerado criminal o terrorista (aunque una minoría de unionistas están dispuestos a tolerar la violencia de los lealistas, considerada como legítima autodefensa contra el IRA). Pero para los nacionalistas el ejército británico no es más que una fuerza de ocupación en un territorio que no les pertenece. La mayoría de los nacionalistas no aprueban la violencia del IRA, pero desde su punto de vista se considera que los paramilitares nacionalistas tienen tanto derecho al uso de las armas como los soldados británicos. Una de las razones que explican el escaso éxito de las fuerzas británicas a la hora de derrotar al IRA se debe a la solidaridad que recibe tanto de nacionalistas irlandeses del norte y el sur del país, así como de la diáspora irlandesa. Otra razón es que a todas las democracias liberales les resulta difícil combatir el terrorismo sin socavar sus propios principios y provocar mayor oposición política.

Consciente de que la lucha militar en Irlanda del Norte conducía a un callejón sin salida y ponía en peligro sus propios compromisos con la democracia, la justicia y los derechos civiles, los sucesivos gobiernos británicos intentaron negociar una fórmula política nueva para la provincia basada en la responsabilidad compartida entre unionistas y lealistas. Pero tales intentos se encontraron con el obstáculo de la oposición unionista, alimentada por la fuerza de la democracia de base dentro de la comunidad. Los líderes unionistas, que estaban dispuestos al acuerdo y al compromiso, se encontraron repetidamente con que no podían contar con el apoyo de sus supuestos seguidores. Cualquier concesión al nacionalismo, en condiciones de violencia paramilitar, simplemente significaba que los líderes moderados perdían a sus votantes ante posiciones más intransigentes como las del reverendo Ian Paisley del Partido Unionista Democrático. Era fácil concluir, en otras palabras, que el problema de Irlanda del Norte no se podía solucionar ${ }^{26}$, y que la lección general a extraer de él era que los Estados democráticos liberales necesitan ser respaldados por la lealtad nacional, encontrándose en graves dificultades donde tal lealtad está seriamente cuestionada ${ }^{27}$.

Sin embargo, durante la pasada década, han tenido lugar en Irlanda del Norte acontecimientos dramáticos que han proporcionado esperanza a todos los observadores, excepto a los más escépticos. Esa década fue testigo de una mayor cooperación entre los gobiernos británicos e irlandés y de negociaciones secretas con representantes del IRA, que desembocaron en el alto el fuego de los paramilitares y en un «proceso de paz» en el cual tanto los nacionalistas como los unionistas fueron inducidos a participar. Éste fue el 
acuerdo firmado en Belfast el día de Viernes Santo de 1998 entre representantes de los unionistas, nacionalistas, y los gobiernos del Reino Unido y de la República Irlandesa, posteriormente ratificados mediante referéndum popular celebrados en el mismo día al norte y al sur de la frontera. El acuerdo, que establecía elaborados compromisos para la responsabilidad compartida ${ }^{28}$ dentro de la provincia fue posible solamente gracias a concesiones de todas las partes que hubieran parecido imposibles solamente unos años antes. La cuestión que necesitamos responder ahora, por tanto, es si podemos atribuir estas señales de esperanza a los cambios posmodernos en la naturaleza del Estado-nación descritos en la sección I (a) de este artículo, y por implicación, si estas nuevas condiciones políticas han cambiado las reglas del juego, haciendo posible tratar con hostilidades nacionales que previamente se habían mostrado irresolubles. Mantendré que este punto de vista tiene ciertos fundamentos, pero solamente después de haber manifestado matizaciones importantes.

\section{II (b). ¿Más allá del Estado-nación en Irlanda del Norte?}

La sección I (b) de este ensayo ha tomado en consideración los diversos cambios en la teoría y práctica del Estado-nación soberano en Europa Occidental, que incluyen la menor relevancia del control militar sobre el territorio, el debilitamiento de la soberanía a través de las relaciones intergubernamentales, la cultura internacional de los derechos humanos, los efectos económicos y geográficos de la globalización y las nuevas interpretaciones de la democracia y la identidad nacional. En esta sección sostendremos que es posible apreciar la influencia de muchos de estos cambios en el proceso de paz en Irlanda del Norte, pero que sus efectos pueden ser fácilmente exagerados y que sería demasiado optimista pensar que los problemas de los Estados multinacionales se han desvanecido en la historia.

No cabe duda de que los cambios en la importancia estratégica y militar del territorio han eliminado algunos obstáculos creando una actitud más relajada hacia las fronteras. La menor importancia de la lealtad se manifiesta en que no se ha demandado a los signatarios del acuerdo de Viernes Santo un juramento de leal$\operatorname{tad}^{29}$. En esta clave se puede interpretar la garantía dada por el Primer Ministro John Major de que «el gobierno británico no tiene intereses estratégicos o económi$\cos { }^{30}$ en Irlanda del Norte y de que no se opondría a una hipotética adhesión de Irlanda del Norte a la República de Irlanda si así lo decidiera la mayor parte de la población. De manera similar puede ser interpretado el debilitamiento de las reclamaciones de la República de Irlanda sobre el territorio del norte. Debemos señalar, sin embargo, que estos acontecimientos pueden ser explicados también desde una óptica más acorde con el entendimiento tradicional del Estado-nación. Es plausible que ambos sean vistos como una renuncia de ambos Estados-nación a anexionar el territorio que consideran propio a costa de incorporar compatriotas que ya no son concebidos como tales. La Declaración Británica reveló, en efecto, que la mayor parte de los británicos no consideraban a los irlandeses del Norte parte de la nación británica (alimentando los temores de los unionistas de ser traicionados y abandonados). Paralelamente ha tenido lugar en la República de Irlanda, un proceso, aún no concluido, de consolidación nacional. El resultado de este proceso es que muchos ciudadanos de la República de Irlanda se muestran hoy reticentes a considerar irlandeses incluso a los nacionalistas del norte, y no digamos a los incorregibles unionistas ${ }^{31}$. Aunque los acontecimientos descritos pueden haber impulsado el proceso de 
paz, arrojan, asimismo, dudas sobre la idea de que representa el desarrollo de un tipo de política que supera la concepción tradicional del Estado-nación.

El intergubernalismo resultante del proceso de paz proporciona una prueba aún mejor de esta transformación. Los gobiernos británicos se han mostrado tradicionalmente muy reticentes a aceptar cualquier tipo de intromisión de otros Estados en asuntos referentes a su soberanía. Margaret Thatcher, que libró una guerra en el Atlántico Sur precisamente para defender territorio británico, fue, sin embargo, quien en el acuerdo anglo-irlandés de 1985 dio los primeros pasos firmes en el inicio de la cooperación con el gobierno de la República de Irlanda en el asunto de Irlanda del Norte, algo que sembró la ira entre los unionistas. El acuerdo de 1998 va más allá, reconociendo formalmente esta «dimensión irlandesa» al crear un Consejo británico-irlandés, así como un Consejo Interministerial que incluye tanto a Irlanda del Norte como a la República de Irlanda. No hay duda de que la intervención irlandesa, aunque rechazada por los unionistas, fue determinante en el desarrollo del proceso de paz e impulsó la intervención del presidente Clinton, del senador norteamericano George Mitchell y del general canadiense John de Chastelain ${ }^{32}$. Debemos tener en cuenta, sin embargo, que esta dimensión externa del proceso no debe ser tomada como prueba de que la Unión Europea haya transformado la soberanía nacional en una cuestión sin relevancia. Es significativo que, más que implicar a sus socios comunitarios, los gobiernos británico e irlandés hayan dirigido su mirada hacia «la diáspora atlántica» y particularmente hacia Estados Unidos, con quien Gran Bretaña e Irlanda han mantenido tradicionalmente una estrecha relación.

La influencia indirecta de la Unión Europea puede notarse en ciertos cambios políticos y culturales en la República de Irlanda que hicieron factible el debilita- miento de las reclamaciones sobre el territorio del norte. Uno de los rasgos tradicionales de la política irlandesa era que cualquier propuesta de esta naturaleza suponía algo así como un suicidio electoral, ya que la identidad irlandesa se encontraba profundamente entrelazada con la historia de la opresión británica. La nueva voluntad de aceptar las fronteras actuales hasta que no exista una mayoría en favor de la unión señala el debilitamiento de los viejos lemas del nacionalismo irlandés. Pero extraer la conclusión de que la nacionalidad ha dejado de importar a los irlandeses sería un tremendo error. Este cambio se ha producido en el contexto de la prosperidad y la modernización activada por los fondos comunitarios y de una posición ventajosa en la nueva economía global. El resultado es un sentimiento de orgullo nacional más relajado y más sólido, distinto de la tradicional preocupación por la religión y los agravios del pasado, del que sin duda ha salido beneficiado el proceso de paz ${ }^{33}$ Este desarrollo también ilustra el hecho de que, en ciertas situaciones, la identidad nacional puede transformarse, aunque, sin embargo, no es prueba del desarrollo de una política de tintes postnacionales.

Una prueba más persuasiva de los efectos de la soberanía compartida que emanan de la construcción europea puede encontrarse en la naturaleza y el diseño del tipo de poder que se establece en el acuerdo de 1998. A diferencia de otros Estados europeos, Gran Bretaña ha tenido poca experiencia en el desarrollo de políticas de coalición y de pacto, acostumbrada al ejercicio de su voluntad política desde un gobierno central elegido por un sistema de representación no proporcional. Sin embargo, en los últimos años, los politólogos británicos han llegado a familiarizarse con las políticas consociativas desarrolladas en otros Estados, mientras sus políticos se han acostumbrado, a través de las acciones de la Unión Europea, a una política global de negociación y cooperación 
bastante diferente de la política de mayorías de Westminster ${ }^{34}$. El proceso que culminó en el acuerdo de 1998 puede ser visto como un producto de esta cultura política en el que se realizó un esfuerzo sustantivo por aglutinar al mayor número de partidos en torno a dicho acuerdo. La gran complejidad de la estructura institucional propuesta podría ser vista como un triunfo de la política posmoderna diseñada para nivelar las concesiones, para difuminar los límites y, mediante la utilización de una ambigüedad calculada, para dificultar la percepción de quiénes son los ganadores y los perdedores del proceso y de dónde descansa la soberanía del poder.

Este desplazamiento desde los dictados de la soberanía hacia la política de pactos significa, en sí mismo, una reinterpretación de la democracia. La flexibilidad de los líderes para negociar e integrar otros puntos de vista es, desde luego, incompatible con la noción de que los líderes deben poner en práctica un mandato popular específico. Los críticos de la democracia consociativa han señalado que, dado que el acuerdo entre élites de grupos rivales puede conseguirse solamente a través de negociaciones privadas, cualquier acuerdo de esta naturaleza puede desencadenar una reacción populista entre seguidores desleales. Los intentos previos por desarrollar un tipo de poder compartido en Irlanda del Norte fracasaron ante la desconfianza de las bases unionistas, y al mismo problema se enfrenta la puesta en práctica del acuerdo de 1998. Una de las estrategias más ingeniosos de la maquinaria institucional ideada por los artífices del acuerdo fue hacer un uso posmoderno del recurso populista al referéndum, con el fin de difuminar la delicada cuestión de quién constituye «el pueblo» en el caso de Irlanda del Norte. El acuerdo fue legitimado a través de dos referendos simultáneos en el norte y el sur celebrados en mayo del 98, lo que permitió que unionistas y nacionalistas vieran cumplidas sus propias defi- niciones de quién constituye el pueblo soberano. El resultado fue positivo y no sólo eso, sino que, por fortuna, la mayoría fue lo suficientemente amplia en el norte como para no dejar duda de que el resultado debía ser aceptado tanto por los unionistas como por los nacionalistas ${ }^{35}$.

La confianza en la capacidad de la política post-nacional y post-moderna para resolver el conflicto nacional no es completamente infundada. Sin embargo, los elementos clave del conflicto se resisten a ser resueltos de la misma manera, algo que hasta ahora ha impedido la plena puesta en práctica del acuerdo. Estos elementos aluden al paradigma del Estado-nación y a cuestiones como la seguridad y la legitimidad del uso de la fuerza, que están profundamente arraigadas en el principio de lealtad nacional y que cristalizan en el estancamiento de las negociaciones sobre el desarme de los grupos paramilitares y, en particular, del IRA. A pesar del alto el fuego unilateral del Ejército Republicano Irlandés, los políticos unionistas rechazaron participar en las negociaciones con los representantes de los terroristas y demandaron que las armas fueran entregadas (o «decomisadas») a cambio de la inclusión del Sinn Fein en las nuevas instituciones políticas ${ }^{36}$. Después de repetidas crisis propiciadas por esta cuestión durante el «proceso de paz», las posturas enfrentadas fueron aparentemente reconciliadas gracias a la acción de la ambigüedad calculada que rodeó al acuerdo. Aunque nada en el texto del acuerdo pudiera obligar al IRA, que no fue una de las partes signatarias, los negociadores y observadores obtuvieron la fuerte impresión de que el IRA estaba comprometido a entregar sus armas en mayo del 2000, lo que suponía un emplazamiento no demasiado urgente para realizar la entrega efectiva. El objetivo táctico de evitar esta cuestión crucial, además del puro oportunismo diplomático, fue desviar la atención política de estos asuntos, con el propósito de que su impor- 
tancia quedara confinada a los niveles propios de una democracia occidental liberal «normal», donde la seguridad militar y la legitimidad de las fuerzas armadas raramente afectan a la vida diaria de los ciudadanos. Desde este punto de vista, lo realmente importante fue el alto el fuego de los paramilitares. La conveniencia política aconseja obviar las actividades pasadas de aquellos implicados en la actual política de pacificación.

Pero la pérdida de importancia de los temas de seguridad y legitimidad solamente se puede lograr gracias a una prolongada experiencia de vida política en condiciones de paz, y ciertamente no a través de formulaciones de ambigüedad calculada. Las divisiones nacionales continúan siendo reforzadas por el temor y la justificación de la violencia. Aún más, la absoluta e innegable solidez de estas divisiones es, de hecho, reconocida y reforzada por las mismas instituciones propuestas en el acuerdo, que garantiza una responsabilidad compartida en el ejercicio del poder entre sectores claramente identificados de la población. A pesar de los intentos de convertir las letales divisiones de la comunidad en el lenguaje inocuo del multiculturalismo invocando al «respeto por las distintas tradiciones» en Irlanda del Norte, los acuerdos concretos parten, de hecho, del supuesto realista de que los partidos que deben compartir el poder representan a comunidades atrincheradas y adscriptivas, y no tanto a individuos libres que pueden transformar su «identidad» y su «cultura» ${ }^{37}$.

En resumen, el proceso de paz de Irlanda del Norte durante la década de los noventa proporciona sólo cierto apoyo a la tesis de que los cambios recientes en la naturaleza del Estado-nación han hecho más fácil afrontar las disputas nacionales en consonancia con la democracia liberal. E incluso este apoyo poco entusiasta de la tesis post-nacional debería ser todavía más matizado, ya que desde el momento de su firma al acuerdo de 1998 le han perseguido las dificultades. El Ejecutivo que resultó del acuerdo fue tardíamente constituido en 1999, pero sólo pasaron dos meses antes de que fuera suspendido por el Reino Unido. Los acontecimientos que causaron este nuevo fracaso fueron los habituales: de un lado, la renuncia del IRA a entregar las armas (sobre la base de que los ejércitos invictos no entregan sus armas y de que «el silencio de las pistolas es suficiente») y, de otro lado, el rechazo de los unionistas a compartir el poder con los representantes de los todavía armados paramilitares (particularmente en un momento en el que los terroristas convictos eran puestos en libertad sin haber cumplido completamente sus condenas). «No permitiremos un gobierno sin la entrega de las armas», decía un popular eslogan de los unionistas. Estas cuestiones no pueden ser consideradas post-nacionales y existe la duda razonable de que puedan ser resueltas en tales términos.

Ciertamente, los problemas democráticos implicados son los problemas tradicionales que se refieren a la responsabilidad ante las bases, no a las políticas posmodernas de negociación global entre élites. Cuando en enero del año 2000 se hizo evidente que el IRA no iba a entregar las armas, el líder del principal partido unionista, David Trimble - recientemente nombrado Primer Ministro en el Ejecutivo negociado-, tuvo que hacer frente a una revuelta en el seno de su propio partido (el partido Unionista del Ulster) por compartir el poder con los representantes de los paramilitares ${ }^{38}$. Para hacer frente al riesgo de que Trimble fuera reemplazado por un líder menos partidario del compromiso, el Secretario de Estado de Irlanda del Norte, Peter Mandelson, tomó la decisión crítica de suspender el trabajo del Ejecutivo, con la esperanza de ganar el tiempo suficiente para negociar la entrega de las armas. Esta «rendición al veto de los unionistas» 
enfureció a los nacionalistas irlandeses, incluyendo el gobierno irlandés ${ }^{39}$. Estos acontecimientos pusieron de manifiesto las crudas realidades que el proceso de paz intentó ocultar bajo una ambigüedad consoladora: que el conflicto entre las dos naciones de Irlanda del Norte sigue siendo en aspectos importantes un juego de suma cero; que en cuestión de seguridad, a pesar de todos los esfuerzos realizados para lograr acuerdos, incluso recurriendo a las estratagemas diplomáticas, se necesitan tomar decisiones que no favorezcan a un sector sobre el otro; y de que, por añadidura, a pesar de la diplomacia intergubernamental, el Reino Unido sigue asumiendo la responsabilidad última en la toma de decisiones, haciendo uso, por tanto, de la misma soberanía que se encuentra en disputa.

En el momento en que se escribe este ensayo, se están realizando esfuerzos, en una atmósfera de cansancio y pesimismo, para reanudar el proceso de paz. Los más optimistas afirman que es posible continuar con el mismo, sobre la base de los avances conseguidos hasta el momento, dado que todos los partidos se muestran a favor de la negociación y de que, a lo largo de la década pasada, han adoptado posturas menos intransigentes, no queriendo ninguno ser culpabilizado del retorno de la violencia. Los pesimistas pueden responder afirmando que la decepción causada por la poca efectividad de los compromisos y la desconfianza generada por el incumplimiento de los términos del acuerdo, pueden hacer más difícil el uso de las estratagemas diplomáticas en el futuro y afianzar las posiciones de los extremistas entre las filas nacionalistas y unionistas. Lo que podemos afirmar con seguridad es que los próximos pasos son tan arriesgados e imprevistos como antes.

\section{Conclusión}

Si desde la experiencia en Irlanda del Norte retomamos las cuestiones teóricas planteadas en la Sección I, ¿qué conclusiones podremos extraer acerca de los problemas de nacionalidad disputada en los Estados democráticos liberales? Las dos posiciones consideradas necesitan alguna modificación. Respecto al argumento post-nacional, destaca una cuestión: la seguridad y sus vínculos con la lealtad. Los debates contemporáneos de la filosofía política tienden a prescindir de las cuestiones de poder, seguridad y lealtad, dando por supuesto la existencia de un Estado democrático liberal fuerte y estable ${ }^{40}$. Pero los Estados democráticos liberales no pueden ser creados a voluntad. Aquellos que existen fueron forjados a partir de una historia de movilización popular cuya solidaridad dotó al Estado de su poder y seguridad. La experiencia reciente en la Europa Occidental ha mostrado que algunos Estados-nación pueden mejorar su estabilidad y su seguridad (y gracias a ello reducir la importancia de la movilización nacional) a través de la cooperación, transformándose gracias a este proceso en entidades distintas al modelo clásico de Estado-nación. En este contexto, muchas de las viejas cuestiones nacionalistas, como los aspectos territoriales o los que se refieren a la seguridad y la lealtad han perdido relevancia. Pero estas transformaciones son locales y contingentes. Para demostrar que en este nuevo milenio las cuestiones de seguridad y lealtad no son conceptos anacrónicos, sólo debemos pensar en la suerte de los ciudadanos de la antigua Yugoslavia. Fueran cuales fueran los acontecimientos y las acciones concretas que condujeron a la disolución del país (y no debemos asumir que se trataba de algo inevitable), es el ejemplo de un Estado que tras perder el apoyo de la solidaridad nacional y la lealtad, no consiguió sobrevivir a la caída del comunismo, minando, con ello, la seguri- 
dad de sus habitantes y dejando el terreno libre a las entidades que pudieran movilizar apoyos: las naciones integrantes. En este caso, la identidad nacional, que durante mucho tiempo fue una identidad individual, se transformó en una pertenencia adscriptiva a una u otra comunidad de destino, cada una de ellas con bases racionales suficientes para considerar a las otras comunidades como amenazas mortales.

Desde el punto de vista de los nacionalistas de la antigua Yugoslavia, el camino más eficaz para la seguridad parece ser tristemente claro: la posesión del propio Estado, lo más libre posible de minorías de dudosa lealtad. Sólo cuando el Estado está firmemente establecido (como en el caso de Croacia) resulta sencillo no preocuparse por la seguridad y detenerse en la consolidación de la democracia liberal y la adhesión a la Unión Europea. Una forma de considerar a Irlanda del Norte es como una «zona de frontera» rezagada en este tipo de construcción estatal ${ }^{41}$. Un lugar donde la nacionalidad no puede ser entendida como una elección personal de la identidad, sino como una cuestión de seguridad comunitaria.

En el marco clásico de los Estados-nación, este conflicto puede resultar irresoluble, justo al borde de la «limpieza étnica». Pero si el caso de Irlanda del Norte tiende a debilitar las posiciones post-nacionales más optimistas, debe conducirnos a cuestionar también la tesis simplista y determinista sobre el Estado-nación señalada en la Sección I (a). Hemos visto que el Estado-nación adopta diversas formas, algunas de las cuales (como en el caso del Reino Unido) incorporan una diversidad considerable dentro de una nacionalidad incluyente. También hemos visto que mientras que la identidad nacional puede ser vista como una entidad inamovible (como en el caso del unionismo), identidades aparentemente sólidas pueden modificarse, como en el caso de los sorprendentes cambios en la identidad nacional en la República de Irlanda. Dichos cambios ni pueden preverse ni pueden ser provocados a voluntad. Pero si las tesis post-nacionalistas dan por sentado precipitadamente la presencia de un Estado lo suficientemente fuerte como para proporcionar seguridad en el interior de su territorio gracias a su facilidad para disponer de la lealtad de su población, la tesis del Estado-nación en su forma más general es demasiado determinista y presta poca atención a lo contingente. Pese a las rígidas líneas de batalla comunitarias, Irlanda del Norte ha presentado durante la última década un drama de acontecimientos y sucesos imprevisibles, lo que nos recuerda, a pesar de todos sus sinsabores, que la política, como afirma Hannah Arendt, es la arena en donde pueden tener lugar milagros realmente imprevistos ${ }^{42}$.

\section{NOTAS}

${ }^{1}$ Reacción de Arendt a la intentona revolucionaria antiestalinista húngara de 1956. «Epilogue: Reflections on the Hungarian Revolution», añadida a la segunda edición de H. Arendt, The Origins of Totalitarianism, Londres, George Allen and Unwin, 1958, p. 482.

2 No ha de confundirse con «multiculturalismo», a pesar de los solapamientos. Como expuse anteriormente, las cuestiones que surgen del multiculturalismo son más fundamentales, ya que la presencia de naciones distintivas plantea retos a la legitimidad, la seguridad y las fronteras del Estado.

${ }^{3}$ Como la mayor parte de los rasgos de la política norirlandesa, la posición de que lo que está en juego es un conflicto nacional (antes que religioso, por ejemplo), es controvertida. Véase sección II (a).

${ }^{4}$ D. Schnnaper, La Communauté des Citoyens: sur l'lée moderne de la Nation, París, Gallimard, 1994. Puede consultarse un desarrollo más completo del argumento de que la identidad nacional es una pre- 
sunción tácita en la teoría y el discurso de la política democrática liberal moderna en M. Canovan, Nationhood and Political Theory, Cheltenham, Edward Elgar, 1996.

${ }^{5}$ Algunos teóricos reconocen la necesidad de solidaridad popular, pero sostienen que puede ser suministrada por el «patriotismo» sin que descanse, necesariamente, en un elemento nacional. Véase, por ejemplo, M. Viroli, Por amor a la patria, Madrid, Acento, 1997. Puede verse una crítica de estas posiciones en M. Canovan, «Patriotism is not Enough», British Journal of Political Science, 30/3, 2000.

6 Canovan, Nationhood and Political Theory; C. Calhoun, Nationalism, Buckingham, Open University Press, 1997.

7 En un estudio sobre los problemas del Estado plurinacional en la Europea del Este poscomunista, Rogers Brubaker señala que, irónicamente, es en los Estados-nación étnicamente homogéneos tales como Eslovenia donde mejor funcionan las concepciones «cívicas» del Estado. Rogers Brubaker, Nationalism Reframed: Nationhood and the National Question in the New Europe, Cambridge, Cambridge University Press, 1996 , p. 105. El caso esloveno no es, por supuesto, concluyente: la riqueza económica de la que disfruta debido a su posición geográfica es también relevante.

8 Considérese, por ejemplo, la continua relación que mantienen en Israel la lealtad nacional y la necesidad y capacidad de defensa.

${ }^{9}$ R. Jackson, «Sovereignity in World Politics: a glance at the conceptual and historical lanscape», en R. Jackson (ed.), Sovereignity at the Millennium, Political Studies Special Issue, 47/3, 1999, pp. 431-456.

${ }^{10} \mathrm{~W}$. Wallace, «The Sharing of Sovereignity: the European Paradox», en Jackson, Sovereignity at the Millennium, pp. 503-521.

${ }^{11}$ D. Held, A. McGrew, D. Goldblatt y J. Perraton, Global Transformations: Politics, Economics and Culture, Cambridge, Polity, 1999, pp. 49-86.

12 D. Held, Democracy and the Global Order: From the Modern State to Cosmopolitan Governance, Cambridge, Polity, 1995.

13 A. Lijphart, Democracy in Plural Societies, New Haven, Yale University Press, 1977.

${ }^{14}$ B. Anderson, Imagined Communities: Reflections on the Origin and Spread of Nationalism, Londres, Verso, 1983.

${ }^{15}$ Por ejemplo, «cada nación es un constructo híbrido, una comunidad imaginada que puede ser reimaginada en versiones alternativas». R. Kearny, Postnationalist Ireland; Politics, Culture, Philosophy, Londres, Routledge, 1997, p. 188.

16 Véase, por ejemplo, Y. Tamir, Liberal Nationa lism, Princeton, Princeton University Press, 1993, pp. 69-73, 163-167.

17 Véase, por ejemplo, N. MacCormick, «What Place for Nationalism in the Modern World?», en National Rights, International Obligations, ed. S. Caney, D. George y P. Jones, Boulder, Westview, 1996, pp. 34-52. A Ingram, «Constitutional Patriotism», Philosophy and
Social Criticism, 22 (1996), 1-18; E. Meehan, Citizenship and the European Community, Londres, Sage, 1993, pp. 146-60.

18 Podemos encontrar una excelente revisión crítica del conflicto en J. McGarry y B. O'Leary, Explaining Northern Ireland: Broken Images, Oxford, Blackwell, 1995. El mejor balance de los antecedentes y el desarrollo del conflicto se encuentra en J. McGarry y B O'Leary, The Politics of Antagonism: Understanding Northern Ireland, 2. ${ }^{\text {a }}$ ed., Londres, Athlone Press, 1996. Los autores realizan un importante esfuerzo de imparcialidad, aunque puede detectarse cierta simpatía hacia las posiciones nacionalistas.

19 La dimensión de los «conflictos» se documenta en el capítulo 1 de O'Leary y McGarry, Politics of Antagonism.

${ }_{20}$ La Constitución de la República de Irlanda de 1937 incluye una cláusula en la que se rechaza la soberanía británica y se reclama el territorio completo de la isla. Sin embargo, en la práctica, los gobiernos irlandeses han aceptado la soberanía británica. Por ello uno de los compromisos del acuerdo de 1998 fue la reforma de la Constitución.

${ }^{21} \mathrm{La}$ división establecía inicialmente un «Estado Irlandés Libre» con un estatus de Dominio semejante, por ejemplo, al canadiense.

${ }^{22}$ La tesis, defendida aquí, de que el Reino Unido es un Estado-nación y de que existe una nación británica, es criticada por algunos analistas que sostienen que en realidad es mejor hablar de un Estado británico que contiene diversas naciones. Véase, por ejemplo, B. Crick, «The English and the British», en B. Crick (ed.), National Identities: The Constitution of the United Kingdom, Oxford, Blackwell, 1991, p. 97. Esta tesis no tiene suficientemente en cuenta, desde mi punto de vista, la peculiaridad de la identidad británica. Véase Canovan, Nationhood and Political Theory, pp. 75-80.

${ }^{23}$ L. Colley, Britons: Forging the Nation 1707-1837, New Haven, Yale University Press, 1992.

${ }^{24}$ En R. D. Edwards, The Faithful Tribe, Londres, Harper Collins, 1999, se ofrece un estudio histórico de la orden de Orange. Su fidelidad es aún más admirable teniendo en cuenta la herencia católica y nacionalista del autor.

${ }_{25}$ Éste no ha sido un temor meramente teórico. Los enemigos de Gran Bretaña, durante la serie de crisis militares que se extienden desde las guerras napoleónicas hasta la Segunda Guerra Mundial, han considerado Irlanda como una base estratégica ideal para la conquista de Gran Bretaña. Como de costumbre, este panorama se ha caracterizado por la complejidad, como muestra la lucha en filas británicas, incluso durante la Segunda Guerra Mundial, de un número cuantioso de irlandeses católicos.

${ }^{26}$ Una revisión completa de los diferentes intentos por lograr un acuerdo puede verse en O'Leary y McGarry, Politics of Antagonism.

27 Puede existir la opción de una secesión pacífica en aquellos casos en los que se da una mayoría bien definida, asentada en un territorio bien delimitado, 
que rechaza la lealtad al Estado, siempre y cuando no exista un grupo bien organizado que sea contrario a la secesión. Pero los problemas que implica la secesión, incluso en circunstancias favorables, no deben ser subestimados. Véase A. Buchanan, Secession, Boulder, Westview Press, 1991.

${ }_{28} \mathrm{El}$ acuerdo supone la transferencia del poder a la Asamblea de Irlanda del Norte, elegida por representación proporcional y encabezada por un Ejecutivo constituido por representantes de diversos partidos. Incluye además un Consejo interministerial Norte-Sur y un Consejo británico-irlandés. Otros elementos mencionados en el acuerdo son el respeto por los derechos humanos, el reconocimiento de ambas «tradiciones» en Irlanda del Norte, la excarcelación anticipada de los presos y un análisis de la estructuras de mantenimiento del orden en la provincia. En último lugar se establece el compromiso de que todos los partidos utilicen sus influencias para conseguir la entrega de las armas en los siguientes dos años. Véase B. O'Leary, «The Nature of the British-Irish Agreement», New Left Review, 233 (1999), pp. 66-96.

${ }^{29}$ O'Leary, «The Nature of the Irish-British Agreement», p. 73

${ }_{30}$ Declaración de adhesión de An Taoiseach, Albert Reynolds y el primer ministro, John Major, el 15 de diciembre de 1993, p. 7.

${ }_{31}$ F. Cochrane, «Any Takers? The Isolation of Northern Ireland», Political Studies (1994) XLII, 378-395; McGarry y O'Leary, Explaining Northern Ireland, pp. 115-119.

${ }^{32}$ Se solicitó a George Mitchell su participación como negociador imparcial durante el proceso. El General De Chastelain presidió la comisión independiente encargada de supervisar el desarme voluntario de los grupos paramilitares.

${ }^{33}$ W. Crotty y D. E. Schmitt, Ireland and the Politics of Change, Londres, Longman, 1998. Más sobresaliente incluso es la aceptación por parte del Sinn Fein, el brazo político del IRA, de participar en el gobierno de Irlanda del Norte bajo la «ilegítima» autoridad británica. Pero esta reacción puede ser considerada un movimiento táctico. La minoría católica en el Norte de Irlanda ha adquirido unas dimensiones y un tratamiento igualitario cada vez más parecido al de los sectores unionistas, lo que ha producido que algunos nacionalistas hayan recurrido, en la lucha por la liberación del territorio, a la estrategia «demográfica», más que al uso de otros métodos violentos. Otra cuestión es si los unionistas que se perciben a sí mismos como una minoría, aceptarían el resultado de un referéndum para anexionarse a la República de Irlanda.

${ }^{34}$ Esto continúa siendo un doloroso proceso de ajuste. Véase Y. Mény, P. Muller y J. L. Quermonne (eds.), Adjusting to Europe: The Impact of EU on National Institutions and Policies, Londres, Routledge, 1996.

35 B. C. Hayes e I. MacAllister, "Who voted for peace? Public Support for the 1998 Northern Ireland
Peace Agreement» (Ponencia presentada al Congreso de la Asociación Norteamericana de Ciencia Política en Atlanta, 1999). Quisiera agradecer al profesor Hayes su permiso para citar este trabajo inédito

${ }^{36}$ El Sinn Fein es considerado generalmente el brazo político del IRA, aunque sus líderes se esfuerzan en resaltar que se trata de una organización política no armada.

37 Los miembros de la Asamblea de Irlanda del Norte deben adherirse al bloque unionista o nacionalista (o formar parte de otros pequeños grupos), con el fin de hacer posible el desarrollo de acuerdos efectivos, consentidos por ambas partes, en la gestión de gobierno. Algunos de los trabajos en donde se documenta que las divisiones comunitarias se han endurecido recientemente son, por ejemplo, el de J. Curtice y L. Dowds, «Has Ireland Really Changed? (Ponencia presentada al Congreso de la Asociación Norteamericana de Ciencia Política en Atlanta, 1999). Me gustaría agradecer al profesor Curtice su permiso para citar en este ensayo su artículo inédito. En Edwards, The Faithfull Tribe, se presentan algunos detalles de la intensificación de la tensión en la polémica en torno a la tradicional marcha de la orden de Orange.

${ }_{38}$ Véase, por ejemplo, la tesis de Donald Horowith, basada en un extenso estudio comparado de sociedades divididas, de que «existe frecuentemente una relación inversa entre la democracia intragrupal e intergrupal. El pacto entre grupos puede ser más sencillo allí donde los partidos articulados en torno a rasgos étnicos no necesitan prestar continua atención a las ventajas políticas que otros grupos competidores obtendrían de los acuerdos realizados entre diversos grupos en conflicto». D. Horowith, A Democratic South Africa? Constitutional Engineering in a Divided Society, Berkeley, University of California Press, 1991, p. 120.

${ }^{39}$ Los nacionalistas cuestionaron la legalidad de esta acción unilateral, suponiendo que mediante la firma del acuerdo, el Reino Unido había cedido parte de sus derechos soberanos sobre la provincia.

${ }^{40} \mathrm{El}$ intento de Shane O'Neill de aplicar los principios habermasianos de la democracia deliberativa al caso de Irlanda del Norte no tiene excesivo fundamento, debido a que ignora el papel de la falta de seguridad y del miedo en la evolución del conflicto. Parece poco probable que los unionistas sigan su recomendación de «embarcarse en un proceso autocrítico de reinterpretación de su propia identidad», mientras existan razones que les hagan temer por sus familias Veáse S. O'Neill, Impartiality in Context: Grounding Justice in a Pluralist World, Albany, State University of New York Press, 1997, p. 189.

${ }^{41}$ McGarry y O'Leary, Understanding Northern Ireland, p. 329.

${ }^{42}$ H. Arendt, «What's Freedom», en H. Arendt, Between Past and Future: Six Exercises in Political Thought, Londres, Faber and Faber, 1961, p. 170. 